\title{
Chapter 2 \\ Dual-Band Planar Inverted F-L Antenna \\ Structure for Bluetooth and ZigBee Applications
}

\author{
Chan H. See, George A. Oguntala, Wafa Shuaieb, J.M. Noras, \\ and Peter S. Excell
}

\subsection{Introduction}

Recently, due to the remarkable advancement of wireless communication technologies, the unprecedented demand of commercial market to have wireless devices was hugely catalysed. To meet this, an innovative antenna design along with effective approaches and technologies should be accordingly developed to meet the growing demand.

In order to maintain the profit margin when offering mobile services, mobile vendors are attempting to reduce the operational cost to attract more customers. Thus, competition has significantly increased in mobile service providers. One approach that facilitates this is the use of the licence-free ISM and UWB bands. Therefore, the ISM band has become more common and popular for use in a broad range of wireless electronic devices, while the UWB spectrum offers the potential for very significant expansion of this.

One of the most widely and widespread applications that uses the ISM bands is IEEE 802.11, wireless Internet (WLAN), namely, 2400 and $5200 \mathrm{MHz}$. The ISM band of IEEE $802.11 \mathrm{~b} / \mathrm{g}$, i.e. $2400 \mathrm{MHz}$, is capable of operating over the range from 2400 to $2485 \mathrm{MHz}$, with data rates of up to 11, $54 \mathrm{Mbps}$. As for the ISM standard of $5200 \mathrm{MHz}$, it covers the frequency range from 5150 to $5350 \mathrm{MHz}$, along with data rate greater than $54 \mathrm{Mbps}$. Thus, to come up with an antenna that operates at

\footnotetext{
C.H. See $(\bowtie)$

School of Engineering, University of Bolton, Deane Road, Bolton, UK, BL3 5AB e-mail: C.See@bolton.ac.uk

G.A. Oguntala • W. Shuaieb • J.M. Noras

School of Electrical Engineering and Computer Science, University of Bradford,

Richmond Road, Bradford, UK, BD7 1DP

P.S. Excell

Institute for Arts, Science and Technology, Glyndwr University, Wrexham, Wales, UK, LL11 2AW 
both bands of WLAN has become a huge challenge. Planar inverted F antennas (PIFAs) [1-3] are considered as a broadly candidate utilized within the WLAN application. This is due to their several advantages including low profile, dual and multi-frequency functions, high power gain and efficiency, low fabrication cost and most importantly mitigating the SAR values compared with other counterpart antennas.

Lately, a number of dual-band antennas along with single feeding point have been reported [1-6]. However, all these designs either have come up with poor radiation features or they are not suitable to be fitted or concealed into compact small portable devices due to space limitation within the chassis. Recently, several antennas with miniaturization approaches have been investigated; these methods include the employment of dielectric with high permittivity, modifying the antenna structures, using shorting wall and pins [7-9].

In recent times, employing the magnetic wall approach has been introduced as one of the effective antenna miniaturization techniques [10-12]. It was unsurprisingly noted that the whole performance of antenna with half-sized geometry with U-slot [10], E-shaped [11] and UWB patch structures [12] has come up with similar results in terms of antenna return loss, gain, far-field and huge size reduction compared to the antenna with full-size structures.

By further modifying the authors' published work in [13-15], the work within this chapter presents a small volume of dual-band planar inverted F-L antennas (PIFLAs) for WLAN applications. The full dimension of the proposed design is $30 \mathrm{~mm} \times 15 \mathrm{~mm} \times 8 \mathrm{~mm}$. This type of suspended antenna was mounted over a metal ground plane with dimensions of $30 \mathrm{~mm} \times 15 \mathrm{~mm}$. This antenna has achieved $50 \%$ size reduction compared to previous published authors' design. All of the analysis was conducted using two commercial software packages [16, 17].

\subsection{Antenna Design Structure and Procedures}

The proposed geometry of the planar inverted F-L antenna (PIFLA) is depicted in Fig. 2.1. In fact this present antenna shares some similarities to previous authors' designs [13]; however, it has a great advantage of only half size of [13]. This huge size minimization was obtained due to the presence of magnetic wall on the antenna surface [10-12]. The key sensitive antenna geometry parameters, which may influence the whole performance, were as follows: L1 $=16.5 \mathrm{~mm}, \mathrm{~L} 2=15 \mathrm{~mm}$, $\mathrm{h} 1=8 \mathrm{~mm}, \mathrm{~h} 2=4.5 \mathrm{~mm}, d=3.5 \mathrm{~mm}$ and $w=0 \mathrm{~mm}$. It should be highlighted that the proposed antenna was from [13]; the only difference is the innovation of reducing the dimension into half while preseving its performance as full-size dimension. The antenna is made of copper with thickness of $0.5 \mathrm{~mm}$.

To better comprehend the operating principle of this miniturised antenna, the current distribution of the antenna with both full $\mathrm{F}$ and $\mathrm{L}$ shapes proposed in [14] and the present half-size design are studied and analysed in Fig. 2.2. It should be noted that maximum currents were induced mainly at the edges of the antenna 


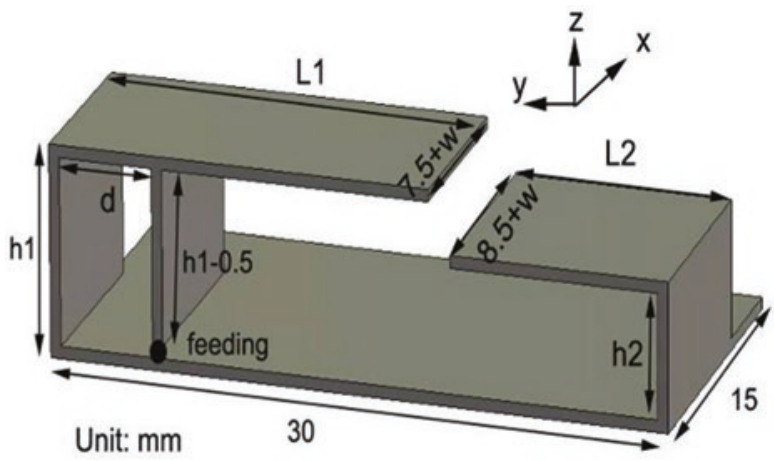

Fig. 2.1 Full geometry of the PIFLA antenna structure

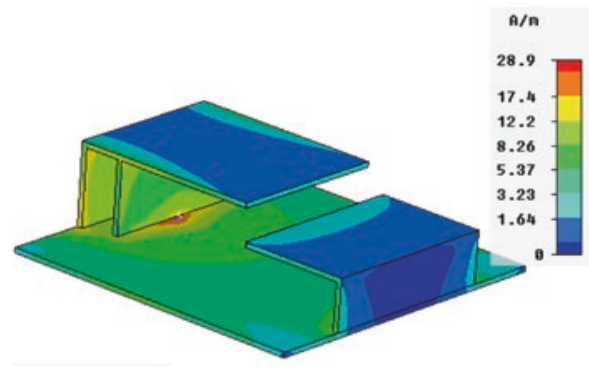

a

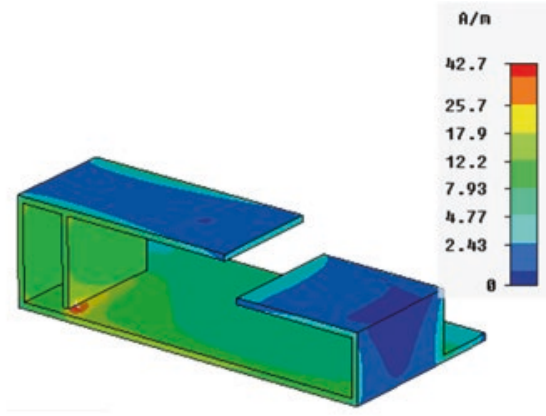

b

Fig. 2.2 Current distributions of (a) full size and (b) half cut PIFLA at $2450 \mathrm{MHz}$

design, while minimum currents were seen at the centre of the antenna. This is because of the presence of magnetic wall. As a result, by following and implementing the technical procedure of cutting half of this full-size structure, we can still assure that the present half-size $\mathrm{F}$ and $\mathrm{L}$ shapes will preserve the same surface current distributions, as illustrated in Fig. 2.2b.

To further verify the concept of miniaturization, the return losses of both fulland the half-size PIFLA are analysed. As shown in Fig. 2.3, the lower band still holds the same impedance bandwidth; however, the bandwidth for the upper band noticeably impairs to be around $12.2 \%(5-5.65 \mathrm{GHz})$ compared to work in [13] and roughly $3.8 \%(5.15-5.35 \mathrm{GHz})$ in comparison to the half structure. It concludes that the size and performance of the present half-size PIFLA antenna makes very suitable for concealing in the casings of portable devices.

The design mechanism and operation procedure of this antenna is further explained in order to offer some physical insight into its operation and the rationale for its geometry. The antenna procedure initially begins by joining the F-shaped radiator with both the L-shaped radiator and a rectangular plate feeding. 


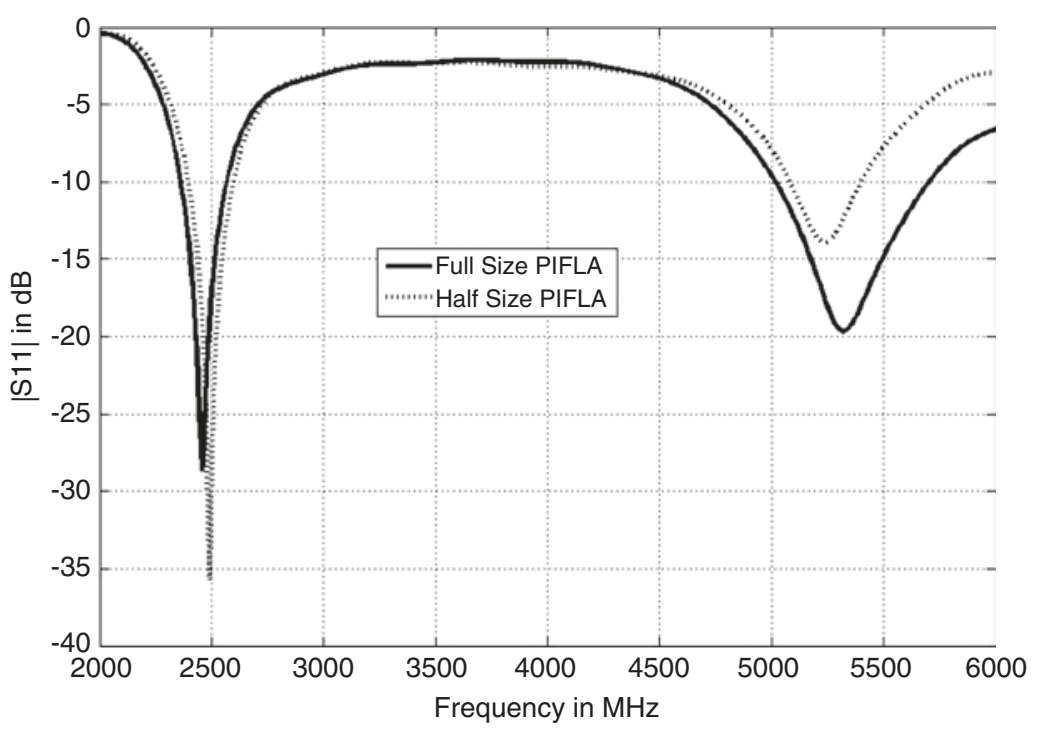

Fig. 2.3 Simulated refection coefficient of full and half size PIFLA design

The F-shaped radiator was mainly made in order to control the lower band of $2400 \mathrm{MHz}$, while the upper band of $5200 \mathrm{MHz}$ was provided by introducing the L-shaped radiator. Generally, exciting the PIFA antenna with the conventional wiring feed normally leads to impedance bandwidth limitation between $4 \%$ and $12 \%$ $[18,19]$. To this end, the feed plate was modified as in [18], in which the bandwidth considerably improved from $18 \%$ to $25 \%$. Therefore, the rectangular feeding plate was selected and applied as the feeding method to enhance the bandwidth in this work.

\subsection{Parametric Analysis}

For further optimizations, a full parametric study was implemented in order to analyse the most sensitive and key antenna parameters against the variation of the antenna impedance bandwidth (defined at reflection coefficient $S_{11}<-10 \mathrm{~dB}$ ) at both the lower and upper bands. In this type of analysis, each simulation needs to be run only with one parameter varied, while other parameters keep constant. The changed and unchanged parameters are depicted in Fig. 2.1. The impedance bandwidth of present design profoundly depends on the isolation between the F- and L-shaped radiators. In fact, analytical methods are not feasible to be reached, and therefore, two EM software packages, namely, HFSS [16] and SEMCAD [17], have been exploited to carry out such investigation. 


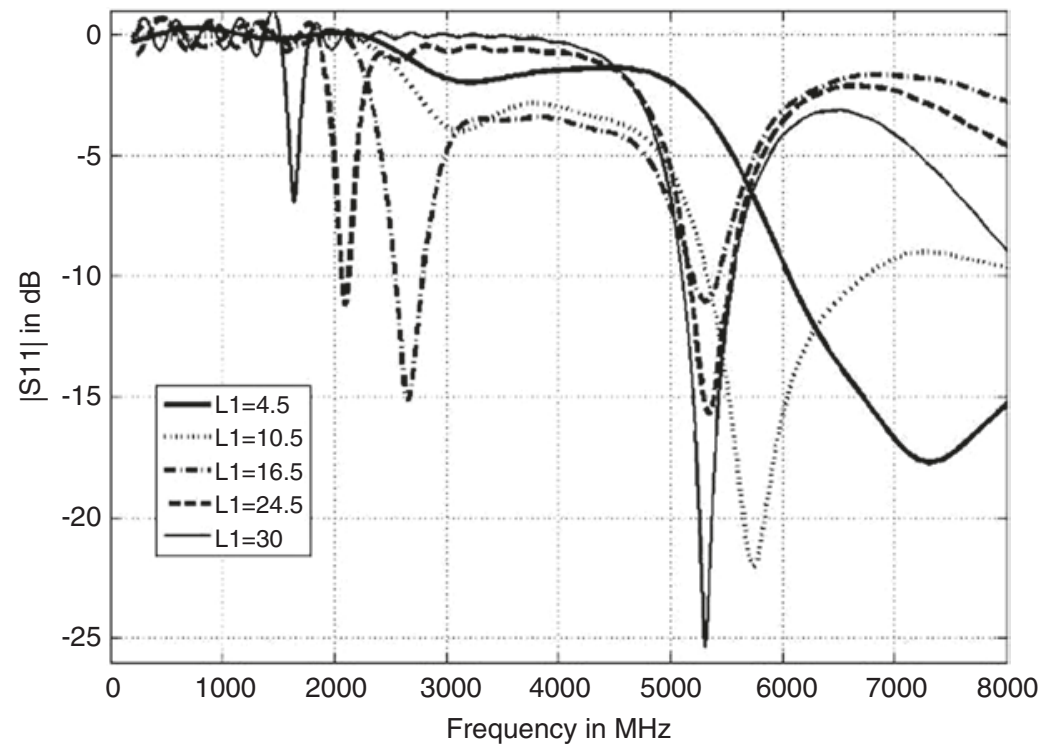

Fig. 2.4 The variation of the length of F-shaped radiator $(L 1)$ against the reflection coefficient

\subsubsection{The Influence of the F-Shaped Radiator Length (L1)}

The effects of changing the electrical length (L1) of the F-shaped antenna mainly appear on the lower band of $2400 \mathrm{MHz}$. The length of the $\mathrm{F}$ shape varied from 4.5 to $30 \mathrm{~mm}$, with increment of $6 \mathrm{~mm}$ as indicated in Fig. 2.4. It should be noted that, in Fig. 2.4, the lower band fluctuates from 2650 to $1600 \mathrm{MHz}$, when the length of $\mathrm{F}$ radiator varied from 16.5 to $30 \mathrm{~mm}$. On the other hand, the variation of L1 does not influence the upper band of $5200 \mathrm{MHz}$. In other words, the upper band seems to be independent of the variation of L1 length. Moreover, when the value of L1 was set at $16.5 \mathrm{~mm}$, both bands of WLAN 2400 and $5200 \mathrm{MHz}$ were, respectively, achieved with an excellent bandwidth impedance matching.

\subsubsection{The Influence of the L-Shaped Radiator Length (L2)}

As previously mentioned, the L-shaped arm is responsible of the high band operation. Thus, the effect of the $\mathrm{L}$ arm was comprehensively analysed as shown in Fig. 2.5. The L-shaped arm length varied from 2 to $24 \mathrm{~mm}$. The variation length of such parameters was elaborated as follows: when the L2 length was set at $2 \mathrm{~mm}$, only a single band at $2800 \mathrm{MHz}$ was achieved, while two bands at 2600 and $5600 \mathrm{MHz}$ were seen when the length of L2 was fixed at $8.5 \mathrm{~mm}$; however, a 


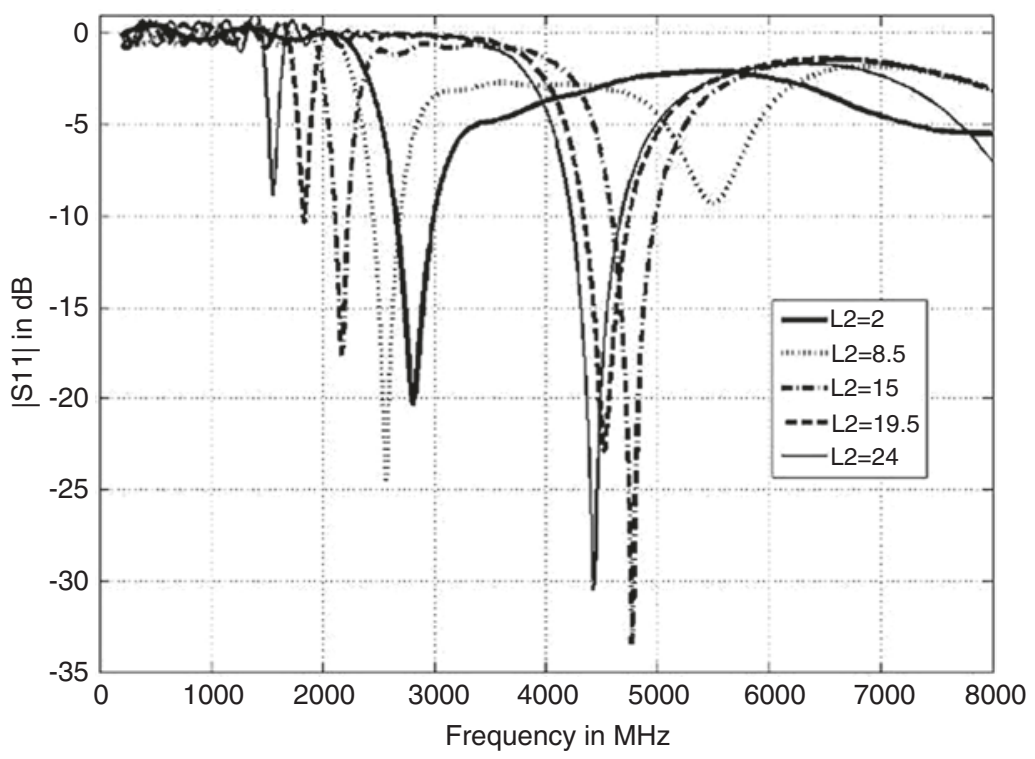

Fig. 2.5 The variation of the length of L-shaped radiator (L2) against the reflection coefficient

weak impedance matching was observed at the band of $5600 \mathrm{MHz}$. When the $\mathrm{L} 2$ length was increased to 19.5 and $24 \mathrm{~mm}$, both desired bands of 2400 and $5200 \mathrm{MHz}$ were not met. On the other hand, it is apparent that the targeted bands of WLAN allocated within this work were reached, when the length of L2 was set at $15 \mathrm{~mm}$.

\subsubsection{The Influence of the F-Shaped Radiator Height (h1)}

The height of the F-structured radiator also mostly affects the upper band of $5200 \mathrm{MHz}$ as clearly shown in Fig. 2.6. The height of F-shaped radiator serves the same role as L1 to control the fundamental resonant mode of the antenna, but it also contributes to the capacitive coupling with the ground plane. The height of this radiator shape was changed from 1 to $8 \mathrm{~mm}$. One should note, when the height was set at 1 and $2.75 \mathrm{~mm}$, the proposed design only operates over a single band around $4000 \mathrm{MHz}$, with impedance mismatching at $2.75 \mathrm{~mm}$ height. However, between the value of 4.5 and $8 \mathrm{~mm}$, no obvious changes on dual-band bandwidth were seen. This has led to the conclusion that the F-shaped height (h1) may take any height between 4.5 and $8 \mathrm{~mm}$ to satisfy and meet the WLAN dual-band of 2400/5200 MHz. 


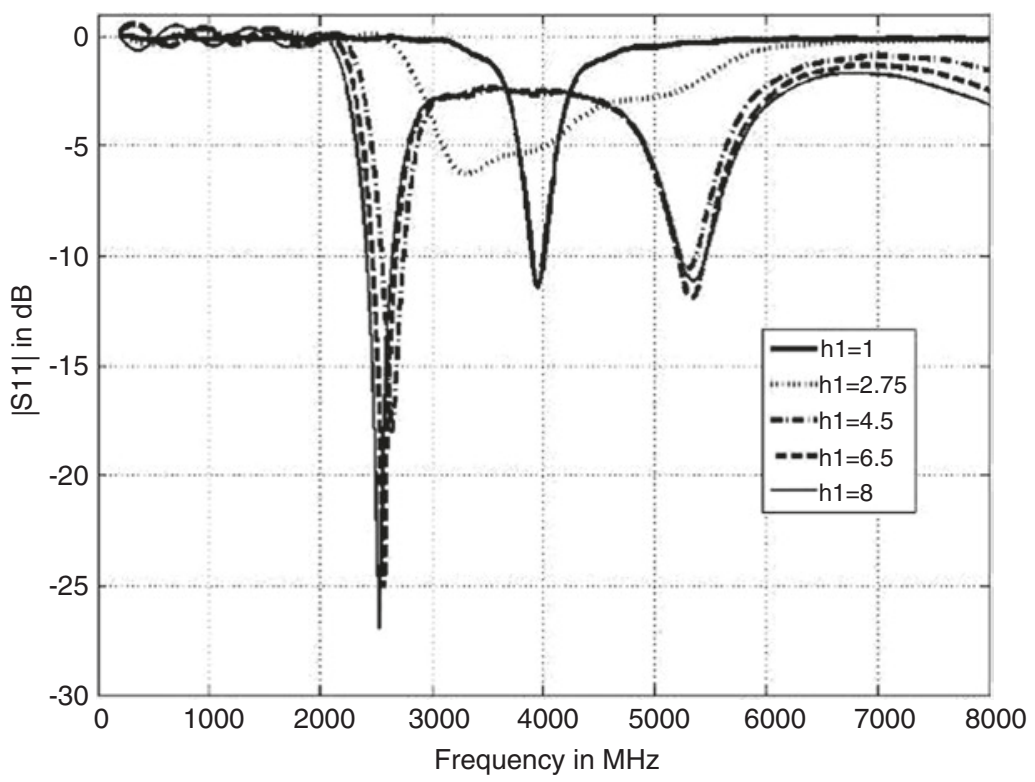

Fig. 2.6 The variation of the height of F-shaped radiator ( $h l)$ against the reflection coefficient

\subsubsection{The Influence of the L-Shaped Radiator Height (h2)}

The impacts of the height of the L-arm are depicted in Fig. 2.7. Both the desired lower and higher bands were seen greatly shifting downwards by varying the height of the L-shaped radiator from 1 to $8 \mathrm{~mm}$. It is also noticeable the impedance mismatch occurs at the higher band when the height are set at the value of 1 and $2.75 \mathrm{~mm}$. Moreover, when the value of h2 was fixed at $8 \mathrm{~mm}$, the proposed antenna covers the band of 2200 and $5000 \mathrm{MHz}$, in which both bands are out of the interest of this work. However, when h2 was set at $4.5 \mathrm{~mm}$, the lower band and upper band both perfectly matched, as well as with a great size reduction of the whole antenna volume.

\subsection{Results and Discussion}

Within the parametric analysis procedure, it was remarkably figuring out that, by carefully selecting the best and optimum values of the structure parameters, the presented antenna with $\mathrm{F}$ and $\mathrm{L}$ arms possibly to be modified and manipulated in order to make the antenna operating within the targeted dual-band of WLAN 


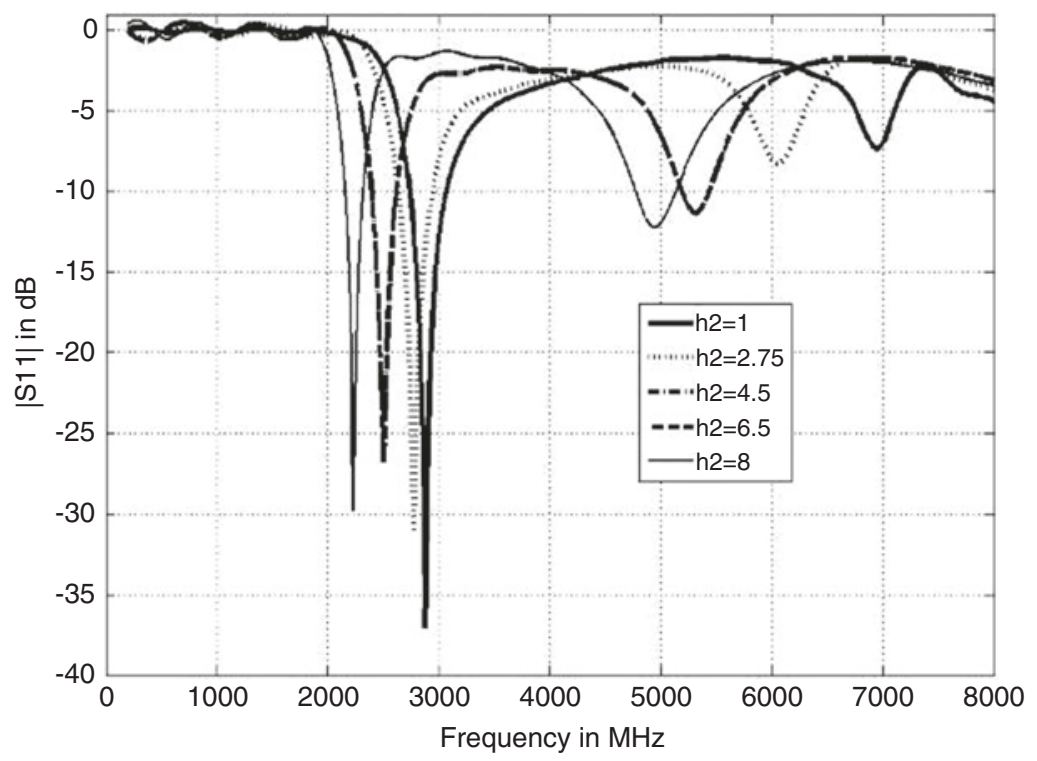

Fig. 2.7 The variation of the height of L-shaped radiator (h2) against the reflection coefficient

Fig. 2.8 Fabricated proposed antenna

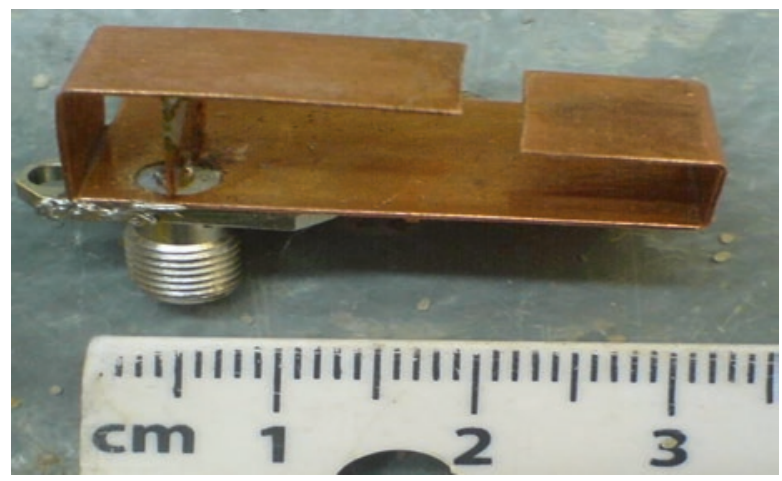

standard allocated within this study. To prove the computed findings, the proposed antenna in Fig. 2.1 was prototyped and tested. The final fabricated antenna including the SMA feeding is shown in Fig. 2.8. The evaluations of the experimental antenna performances in terms of reflection coefficients $\left|S_{11}\right|$, radiation patterns, power gains and radiation efficiencies were carried out in a $3 \times 4.5 \times 5 \mathrm{~m}^{3}$ anechoic chamber. It should be noted that the return loss of the fabricated antenna was measured by using a vector network analyser (model: HP8510c), while the antenna radiation patterns and power gains were investigated inside the anechoic chamber by using gain comparison method.

For validation purposes, both the measured and calculated antenna reflection coefficient of the full-size and half-size PIFLAs is illustrated in Fig. 2.9. Dual reso- 


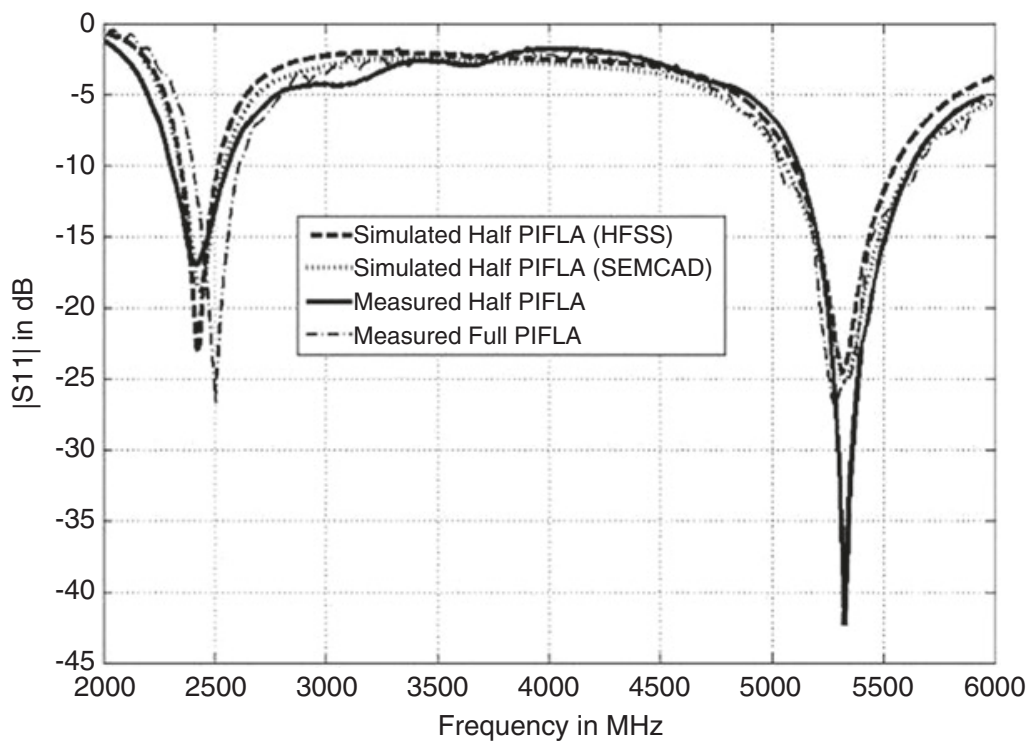

Fig. 2.9 Measured and simulated reflection coefficients $\left|S_{11}\right|$ for the dual-band PIFLA

nant frequencies in the range of reflection coefficient $\left|S_{11}\right| \leq-10 \mathrm{~dB}$ are seen, i.e. 2450 and $5350 \mathrm{MHz}$. A relative bandwidth of around $12 \%$ was obtained at the lower band of $2400 \mathrm{MHz}$, while a bandwidth of $10.2 \%$ was provided at the higher band of $5200 \mathrm{MHz}$. This satisfies the allocated services of IEEE802.11b/g frequency band (2400-2485 MHz) and IEEE $802.11 \mathrm{a}(5150-5350 \mathrm{MHz})$ band, respectively. It is undoubtedly that the half-size proposed F-L antenna demonstrates same impedance bandwidth over the two WLAN bands, in which such feature has given this antenna an additional advantage of the full-size PIFLA structure as the size reduction is significantly accomplished while same bands are maintained.

Figure 2.10 explains the computed and practical power gains of the proposed structure over the frequency ranges from 2400 to $2480 \mathrm{MHz}$ and 5000 to $5600 \mathrm{MHz}$, respectively. It should be noted that the power gain values at the lower band vary from 2.6 to $3.5 \mathrm{dBi}$, while values range $4.5-5.2 \mathrm{dBi}$ may be seen at the upper band. Moreover, the power gains of the miniaturized design are in good agreement with the full-size design. This is again another benefit added to the proposed design, since it can propose similar power gain with a smaller antenna design compared to the full-size design.

The simulated and measured radiation efficiencies of both full and half sized antennas are indicted in Fig. 2.11. The simulated efficiency was produced with the help of previously mentioned software [16,17], while the measured one was generated by suing the Wheeler Cap measurement method [20-22] (Fig. 2.5). The radiation efficiencies at the lower bands of both full- and half-size structure range from 0.96 to 0.98 and 0.93 to 0.94 , respectively; values around $93.5 \%$ and $89 \%$ are obtained at the upper bands of both antenna versions. 

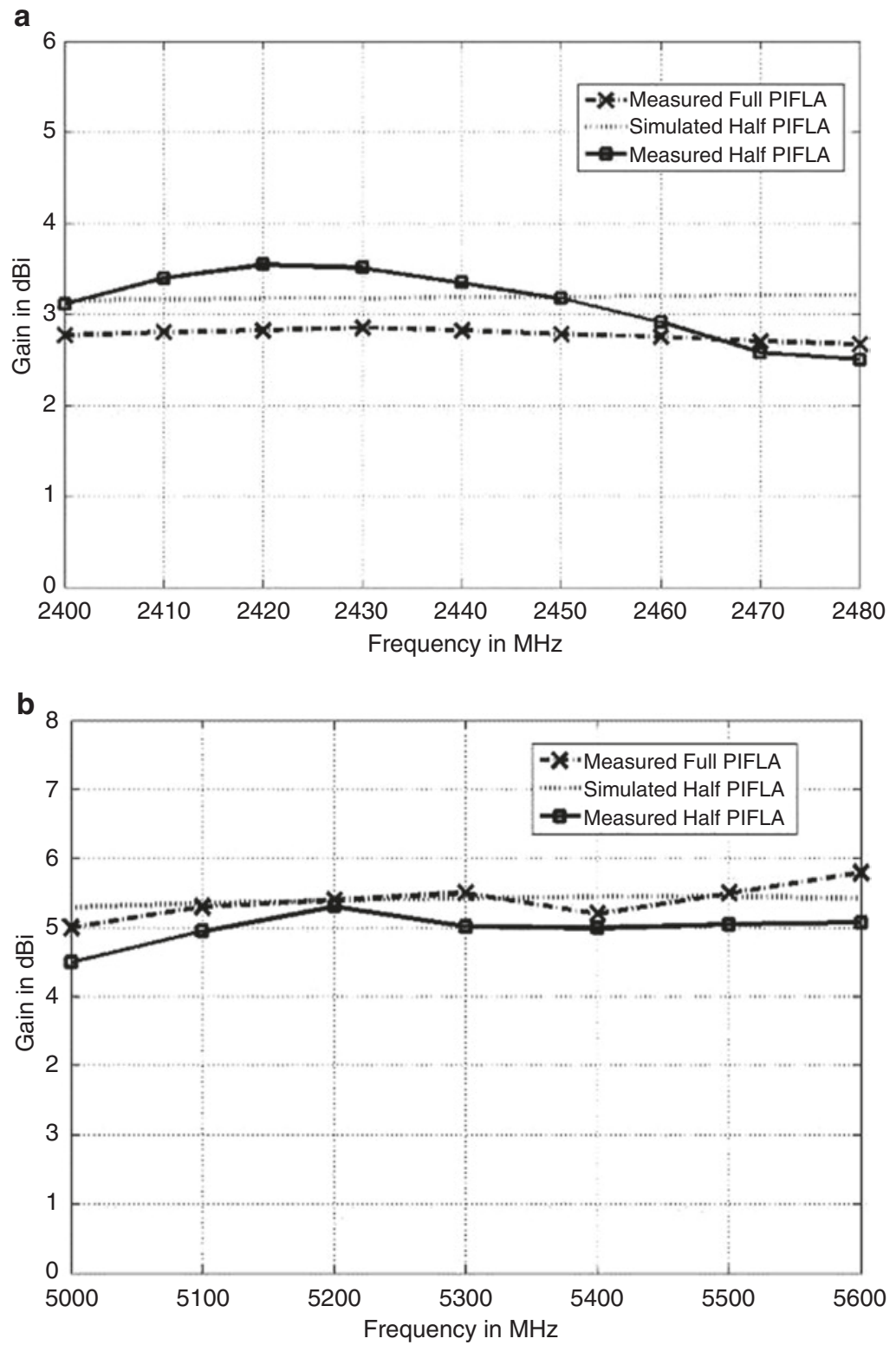

Fig. 2.10 Simulated and measured gains for the proposed design: (a) lower band and (b) higher band

The simulated and measured radiation patterns are depicted in Fig. 2.12. The computed far field data was generated by the EM simulators. However, the measurement setup with a calibrated broadband horn (EMCO type 3115), which was con- 

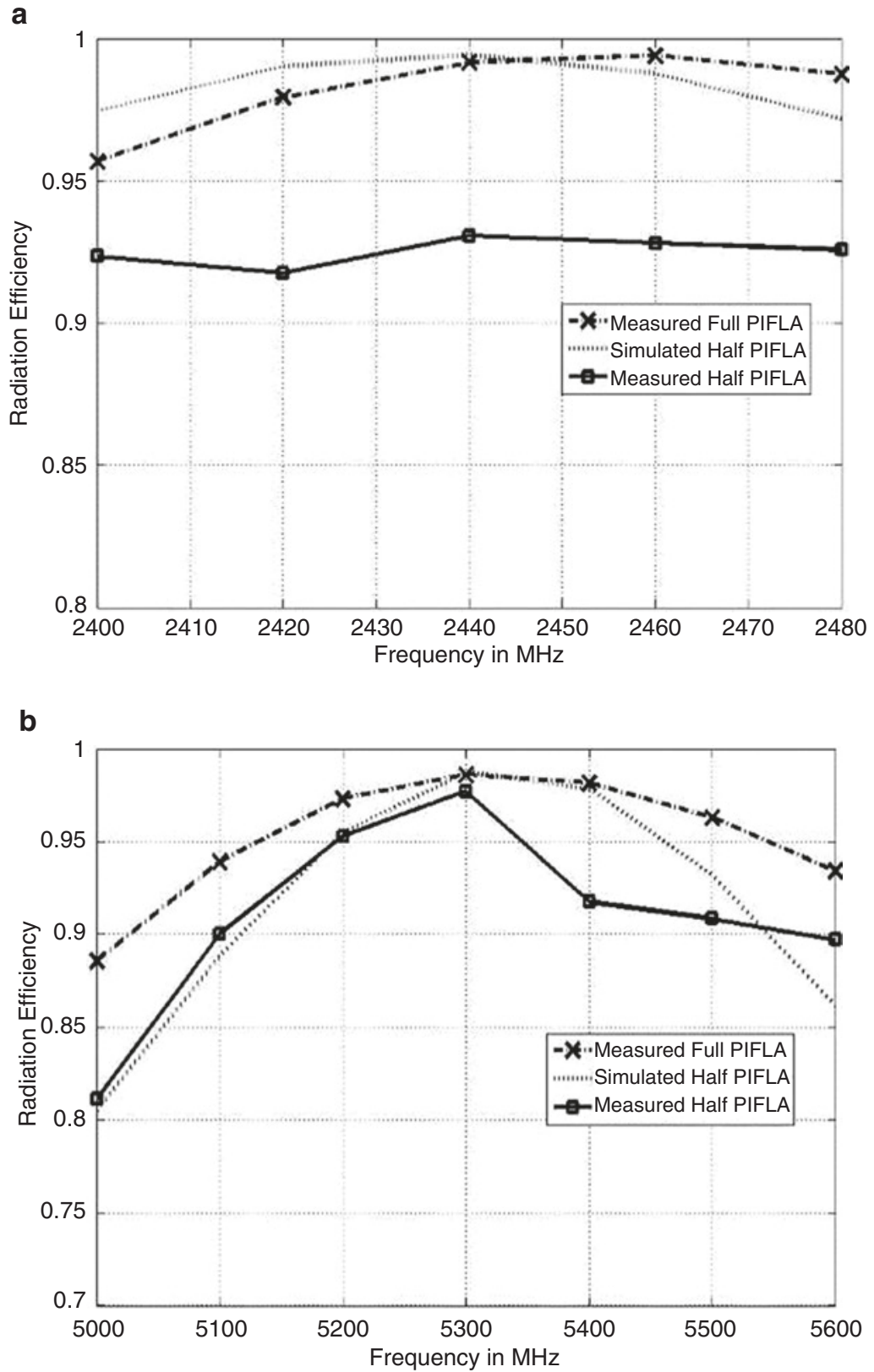

Fig. 2.11 Simulated and measured radiation efficiencies for proposed design at (a) lower band and (b) higher band 

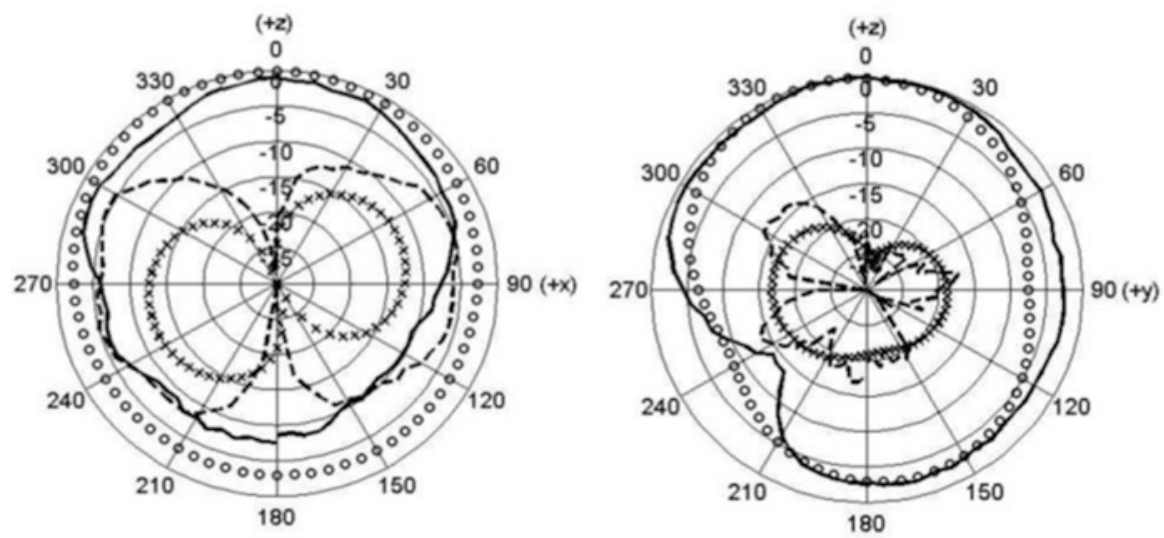

a
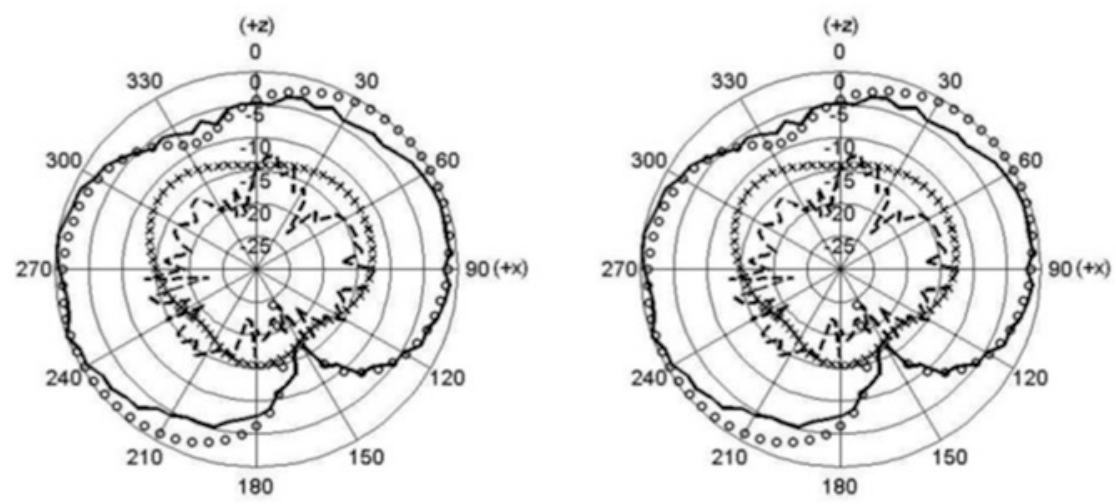

b

Fig. 2.12 Normalized simulated and measured radiation patterns of the proposed design for two planes ( $x-z$ plane, $y-z$ plane) at (a) $2400 \mathrm{MHz}$ and (b) $5200 \mathrm{MHz}$; 'xxxx' simulated crosspolarization, 'oooo' simulated co-polarization, '------' measured cross-polarization, '_- ' measured co-polarization

sidered as the reference antenna, also with a distance of $4 \mathrm{~m}$ with the proposed antenna (antenna under test), was used to test the antenna radiation patterns. Two pattern cuts $(x-z$ and $y-z$ planes) were selected for the both bands.

Figure 2.12 illustrates both the simulated and measured co-polar and cross-polar radiation patterns in the $\mathrm{x}-\mathrm{z}$ and $\mathrm{y}-\mathrm{z}$ planes at the targeted dual-band of 2400 and $5200 \mathrm{MHz}$ for the miniaturized PIFLA. One can observe that both simulated and measured outcomes of the antenna radiation patterns are in reasonable matching. Moreover, in comparison with the radiation patterns for antenna with full $\mathrm{F}$ and $\mathrm{L}$ shaped in [14], it seems that both designs show indistinguishable radiation patterns. This proves that exploiting the size reduction approach within this study does not influence or impair the antenna radiation patterns. 


\subsection{Conclusion}

A planar inverted F-L antenna (PIFLA), along with a size reduction approach with a simple geometry, has been modelled, investigated and measured. By applying an optimization analysis as well as miniaturization techniques, a novel PIFLA structure with almost 50\% size reduction for use in WLAN applications has been accomplished. By compromising both the size and bandwidth limitations, the present design has come with a compact volume $30 \mathrm{~mm} \times 15 \mathrm{~mm} \times 8 \mathrm{~mm}$, while covering the required operating frequency bands. The simulated model then has been fabricated and tested, in which its measured results were compared to the computed results obtained from the EM simulators. Both the experimental and calculated findings prove that the present antenna structure may be seen as a promising candidate for smart and future mobile applications.

\section{References}

1. L.O. Soo, B.P. Koh, P. Song, L. Lau, From a simple IFA to a dual band PIFA. International Workshop on on Antenna Technology, Chiba University, Japan, Mar 2008, pp. 386-389

2. Y.-B. Kwon, J.-I. Moon, S.-O. Park, An internal triple-band planar inverted-F antenna. IEEE Antennas Wireless Propag. Lett. 2, 341-344 (2003)

3. C.-T. Lee, K.-L. Wong, Uniplanar printed coupled-fed PIFA with a band-notching slit for WLAN/WiMAX operation in the laptop computer. IEEE Trans. Antennas Propag. 57, 1252 1258 (2009)

4. D. Liu, B. Gaucher, A new multiband antenna for WLAN/cellular applications, IEEE Vehicular Technology Society Conference, Milan, vol. 1, Sept 2004, pp. 243-246

5. H.-C. Tung, S.-T. Fang, K.-L. Wong, Printed dual-band monopole antenna for $2.4 / 5.2 \mathrm{GHz}$ WLAN access point. Microw. Opt. Technol. Lett. 35(4), 286-288 (2002)

6. D.D. Krishna, M. Gopikrishna, C.K. Anandan, P. Mohanan, K. Vasudevan, CPW-fed Koch fractal slot antenna for WLAN/WiMAX applications. IEEE Antennas Wireless Propag. Lett. 7, 389-392 (2008)

7. A.K. Skrivervik, J.-F. Zurcher, O. Staub, J.R. Mosig, PCS antenna design: The challenge of miniaturization. IEEE Antennas Propag. Mag. 43, 12-27 (2001)

8. C.S. Lee, K.-H. Tseng, Size reduction of microstrip antennas. Electron. Lett. 37, 1274-1275 (2001)

9. A.K. Shackelford, K.F. Lee, K.M. Luk, Design of small-size wide bandwidth microstrip-patch antennas. IEEE Antennas Propag. Mag. 45(1), 75-83 (2003)

10. A.A. Deshmukh, G. Kumar, Half U-slot loaded rectangular microstrip antenna, in IEEE Antennas and Propagation Soc. Intl. Symp., Columbus, vol. 2, 2003, pp. 876-879

11. R. Chair, C.-L. Mak, K.-F. Lee, K.-M. Luk, A.A. Kishk, Miniature wide-band half U-slot and half E-shaped patch antennas. IEEE Trans. Antennas Propag. 53(8), 2645-2651 (2008)

12. L. Guo, S. Wang, X. Chen, C. Parini, Miniaturised antennas for UWB communications, Proc. European Conf. on Antennas and Propagation, Berlin, Germany, Mar 2009, pp. 3774-3778

13. C.H. See, R.A. Abd-Alhameed, D. Zhou, P.S. Excell, Dual-frequency planar inverted F-Lantenna (PIFLA) for WLAN and short range communication systems. IEEE Trans. Antennas Propag. 56, 3318-3320 (2008)

14. C.H. See, R.A.Abd-Alhameed, D. Zhou, E.A. Elkhazmi, M.M. Abusitta, K.N. Ramli, P.S. Excell, Miniature dual-frequency half planar inverted F-L-antenna for WLAN/cellular 
applications, in the proceeding of Microwave Conference, 2009. APMC 2009, Asia Pacific, 7-10 Dec 2009, pp. 2802-2804

15. C.H. See, R.A. Abd-Alhameed, D. Zhou, P.S. Excell, A planar inverted F-L antenna (PIFLA) with a rectangular feeding plate for lower-band UWB applications. IEEE Antenna Wireless Propag. Lett. 9, 149-151 (2010)

16. High Frequency Structure Simulator (HFSS), version 11, Ansoft LLC, Pittsburgh

17. SEMCAD X, version 14, Schmid \& Partner Engineering AG, Zurich

18. R. Feick, H. Carrasco, M. Olmos, H.D. Hristov, PIFA input bandwidth enhancement by changing feed plate silhouette. Electron. Lett. 40, 921-922 (2004)

19. H. Nakano, N. Ikeda, Y.-Y. Wu, R. Suzuki, H. Mimaka, J. Yamauchi, Realization of dualfrequency and wide-band VSWR performances using normal-mode helical and inverted-F antenna. IEEE Trans. Antennas Propag. 46, 788-793 (1998)

20. R.W. Johnston, J.G. McRory, An improved small antenna radiation-efficiency measurement. IEEE Antenna Propag. Soc. Mag. 40(5), 40-48 (1998)

21. H. Choo, R. Rogers, H. Ling, On the wheeler cap measurement of the efficiency of microstrip antennas. IEEE Trans. Antennas Propag. 53(7), 2328-2332 (2005)

22. M.-C. Huynh, W. Stutzman, Ground plane effects on planar inverted-F antenna (PIFA) performance. IEE Proc.-Microw. Antennas Propag. 150(4), 209-213 (2003) 